\title{
Editorial
}

\section{The Role of the Performing Arts in Improving and Maintaining our Well-being during \& post-COVID Pandemic}

\author{
Irina Roncaglia*a
}

[a] The National Autistic Society (NAS), United Kingdom.

\section{Abstract}

This editorial presents some key domains with explorations of the benefits of the Performing Arts and how these can be practically applied globally across our current COVID pandemic landscape and beyond. More than ever before there is a need to acknowledge that, despite complex logistics and ethical and economic issues in delivering effective performing arts programs for health and well-being, its evidence-based benefits cover a range of disciplines, from psychology to anthropology, sociology to medicine making the approaches transdisciplinary, and enriching end-users lives throughout, but not exclusively, in their coproduction. Performing arts programs may also offer the way for alternative solutions and pathways where conventional approaches may have reached the end of the road and helping to embed biopsychosocial models of wellbeing promotion through social prescribing. The COVID pandemic has offered the opportunity to revisit how we look at prevention, promotion, management, and treatment of ill-health in unprecedented adversity. This editorial hopes to start this important conversation.

Keywords: Performing arts; well-being; COVID; prevention; promotion; management; treatment.

\section{Table of Contents}

Psychomotor domains

Cognitive domains

Affective domains

Social Intent \& Engagement

Aesthetics and its appreciation

Discussion: Concluding Comments

References 
Psychological Thought, 2021, Vol. 14(1), 1-8, https://doi.org/10.37708/psyct.v14i1.606 Received: 2021-03-10. Accepted: 2021-04-02. Published (VoR): 2021-04-30.

Handling Editor: Natasha Angelova, South-West University "Neofit Rilski", Blagoevgrad, Bulgaria.

*Corresponding author at: Chartered Practitioner Sport \& Exercise Psychologist, The National Autistic Society (NAS), United Kingdom. E-mail: irina@roncaglia.co.uk

This is an open access article distributed under the terms of the Creative Common Attribution License (https://creativecommons.org/licenses/by/4.0), which permits unrestricted use, distribution, and reproduction in any medium, provided the original work is properly cited.

The potential value of performing arts in promoting positive physical, psychological, social spiritual and cultural well-being and health as defined by WHO (1948) is in recent years become even more prevalent following a large evidence-based review that looked at over 900 publications, of which included were over 200 reviews, systematic reviews, metaanalyses, and meta-syntheses that covered over 3000 studies, and over 700 further individual case studies (Fancourt \& Finn, 2019). It is not new that the COVID pandemic has brought and continues to bring devastating outcomes which have influenced perhaps for a foreseeable future the way we live, work and play. What perhaps is not so apparent, or at least not yet, is the focus on our ability to have to live with uncertainty, with constant change and after 12 months since the pandemic started, having to accept and adapt still to the unknown. The burden on our health, physical, mental and even emotional, social and cultural will probably be observed and felt for many years to come. In this editorial, the role of performing arts in its entirety and wholeness is discussed in light of these burdens on our health and how they have and can be seen not merely as an entertainment activity, which is as fundamental as a child's play in their cognitive, social and emotional development (Austin, 2020; Gendlin, 1997), but as a vehicle to promote, prevent, manage and even treat some illhealth conditions and help us to restore wellbeing, balance and togetherness in our humanity. WHO (1948) defines health as "a state of complete physical, mental and social well-being and not merely the absence of disease or infirmity" firmly linking health within society and culture. Recently however, health has been conceptualized more as a dynamic process, as it includes at its core, having an opportunity and more significantly the capacity to self-manage, through positive approaches, psychological resilience, and autonomy our own health and wellbeing. In a recent publication the WHO promotes that 'Health and wellbeing are public goods and assets for human development that contribute to strong, dynamic and creative societies '(WHO, 2019). 
Looking at some of the recent evidence of the benefits of the arts, and their effects on our health, and using some principles of thematic analysis (Marks \& Yardley, 2004) to grouping together themes which stems from past reviews on the general engagement in the arts, this editorial presents how our subjective and collective wellbeing can be nurtured in promoting, preventing, managing and ultimately treating - when necessary - the onset of ill health.

Five main domains (see Table 1 below) are presented and discussed in highlighting emerging benefits, which are intricately linked to when individuals either subjectively or collectively are engaged, coproducing, learning, sharing, observing actively or passively, a performing art activity.

Table1.

Learning Domains Performing Arts, Dance and Music.

\begin{tabular}{|c|c|c|c|c|}
\hline Psychomotor & Cognitive & Affective & Social & Aesthetic \\
\hline Biomechanics & $\begin{array}{l}\text { Choreographic } \\
\text { concepts }\end{array}$ & $\begin{array}{l}\text { Emotional status | } \\
\text { Feelings }\end{array}$ & $\begin{array}{l}\text { Positive } \\
\text { interactions with } \\
\text { others }\end{array}$ & $\begin{array}{l}\text { Appreciation of } \\
\text { beauty }\end{array}$ \\
\hline $\begin{array}{l}\text { Physiological } \\
\text { changes through } \\
\text { movement }\end{array}$ & $\begin{array}{l}\text { Terminology \& } \\
\text { Narrative }\end{array}$ & Attitudes & Teamwork & Form | Shapes \\
\hline $\begin{array}{l}\text { Understanding } \\
\text { through } \\
\text { embodiment }\end{array}$ & $\begin{array}{l}\text { History \& Culture } \\
\text { (of Dance or other } \\
\text { performing arts } \\
\text { forms) }\end{array}$ & Preferences & $\begin{array}{l}\text { Participation } \\
\text { and } \\
\text { engagement }\end{array}$ & $\begin{array}{l}\text { Appreciation of } \\
\text { Opposites }\end{array}$ \\
\hline $\begin{array}{l}\text { Coordination, } \\
\text { Speed, }\end{array}$ & $\begin{array}{l}\text { Pattern of thinking } \\
\text { (negative | } \\
\text { positive) }\end{array}$ & Values | Beliefs & $\begin{array}{l}\text { Social } \\
\text { Engagement }\end{array}$ & Creativity \\
\hline
\end{tabular}

\section{Psychomotor domains}

The COVID pandemic and the associated restrictions on our lifestyles, and ability to move and navigate in our communities have undoubtedly increased the amount of time we spend either indoors or inactively and sedentary behaviuor. And whilst there has been a flourish of online fitness classes and other forms of exercise, their adherence and sustainability has posed its challenges. It is predicted that musculoskeletal conditions are on the rise and will continue to increase if preventative measures are not put in place by ensuring that engagement in enjoyable and meaningful movements in whatever form, is not sustained consistently. Performing arts, dance classes, movements sessions provide a great 
opportunity in ensuring that whilst physical activity is learned, explored and produced, end users and participants continue and maintain their engagement with long lasting effects and outcomes. There has been a plethora of evidence on the physical benefits of exercise in whichever form this is embraced. Performing arts, dance, movement sessions can provide a unique opportunity for individuals to not only benefit from physical activity, and its associated positive outcomes such as cardiovascular, fitness, bone and muscle strength, immune system activation and strengthening, but also benefits associated to increased attention, focus, coordination, balance, flexibility and strength and conditioning (Guss-West \& Gabriele, 2016).

\section{Cognitive domains}

Engagement in performing arts can provide opportunities and great benefits not only for our physical health, but also in the way our brains and thinking operates. Through greater awareness in our breathing, perceptions, and awareness of our movements, there is evidence for positive reduction of muscular hypertension, range of functional motion, an increase in the quality of our movements and its fluidity, and the promotion of automatic micro-adjustment which can reinforce movement confidence (Wulf, 2013). Engagement in arts projects can creatively support and contribute to our positive self-esteem, autonomy, a sense of competence and a sense of belonging (Ryan \& Deci, 2007). These are universal basic psychological human needs that contribute to our wellbeing and wellness. The arts have contributed to the reduction of stigma around heath issues, through representations in media storylines, and participation in arts programs which has promoted empathy, positive attitudes towards people with mental and physical ill-health and has promoted resilience among people with ill-health conditions (WHO, 2019).

\section{Affective domains}

Performing arts can provide a platform for the expression of emotional arousal and states, a psychological safe space to explore moods, emotions, feelings which have been untold or hidden (Fancourt, 2017). Through an empathic approach, it offers an opportunity to learn how to better understand and even manage difficult and persistent emotional states, through self-regulation and self-expression which is creative, positive and constructive rather than expressed and acted potentially through maladaptive and risky behaviours and responses. 
Participation in an art event, collaboration and even coproduction can provide an opportunity to explore our own (and others) values and belief systems and provide an opportunity to better understand others' perspectives. The enjoyment offered and experienced through an art based activity can provide discovery, self-growth, enrichment and fulfilment. As recently discussed by a number of companies' artistic directors, the opportunity of empathy and togetherness can provide a space for awareness and - if needed - optimism, hope and recovery (BBC 4, 2021).

\section{Social Intent \& Engagement}

Recent evidence suggests that art-based activities can promote social connections, interactions and positive social experiences. When we share a collective space in the making, participating, engaging in an art based task, whether that is in the form of storytelling, poetry, dance or visual arts, we nurture one of the fundamental psychological basic human needs: a sense of belonging (Ryan \& Deci, 2007). There is some strong evidence that dance for Parkinson's disease patients, projects run nationally in the UK and internationally can, not only bring physiological benefits, but an opportunity for those affected by potential isolation and loneliness, a real lifeline of hope, togetherness and a sense of purpose (Kaufman, 2016). The social engagement fostered through the performing arts, can again help rediscover what it means sharing spaces together, being in tune with each others, enjoying meaning making together.

\section{Aesthetics and its appreciation}

Appreciation of beauty, whether in the form of shapes, music, color, or complex systems brings positivity and hope rather than helplessness (Seligman, 2011; Seligman \& Csikszentmihalyi, 2000). Creativity expands our minds into possibilities and provides an internal motivation to thrive even and despite adversities and setbacks. The COVID pandemic has provided us with a unique opportunity to nurture and discover meaning in the way we practice noticing and appreciation of beauty, harmony, and complexity. It has given us the time and space to realize that taking a pause, taking a moment of reflection and even solitude, can bring meaningful discovery. Cultivating and even investing in these activities can help prevent both in the short and long term, physical and psychological ill health, and reduce stress and anxiety. Appreciating creativity, in its process and journey can provide 
solace and fortitude, drive and motivation which post-COVID pandemic is and will be greatly needed.

\section{Discussion: Concluding Comments}

Performing arts and specifically dance can be setting the stage for lifelong understanding of what it means to be observed, compared, assessed, and evaluated. These are fundamental life-skills necessary for growth, development, and maintenance of our wellbeing and a sense of community. Through performing and specifically dance forms, we contribute to our love of the self (and others) and nurture an ability to process the inherent benefits of dance as an art form. Through professional growth we continue to develop our own internal dialogue with embodiment, movement, sense and meaning making, creativity, and expressive forms on how these are understood and communicated.

Internal dialogues become the vessel for expression of the 'untold' or of the 'inexpressible' because holding too heavy and painful emotions, especially during the current landscape of a pandemic we are all part of, can lead to negative health outcomes. Finding a common language that can be understood, embraced, empathized and ultimately released can help us looking after ourselves and each other in the prevention of ill-health, management and treatment of conditions which may be short or long-term, temporal, or chronic, and help nurture an agency in the promotion of subjective and collective well-being.

\section{Funding/Financial Support}

The author has no funding to report.

\section{Other Support/Acknowledgement}

The author has no support to report.

\section{Competing Interests}

The author is a member of the Editorial board of Psychological Thought. 


\section{References}

Austin, K. (2020). NDEO Assessments for early childhood dance education. IADMS iConference. Accessed on: 12, January 2020. https://iadms.org/our-programs/elearning/iconference/

BBC (2021). Imagine 2021: We'll Be Back? Accessed on: 9, February 2021.

www.bbc.co.uk/iplayer/episode/m000s5m0

Bruner, J. (1993). Acts of Meaning. Harvard University Press.

Fancourt, D. \& Finn, S. (2019). What is the evidence on the role of the arts in improving health and well-being? A scoping review. World Health Organisation, Accessed on: 24 January, 2021. https://www.euro.who.int/en/publications/abstracts/what-is-the-evidence-on-the-role-of-thearts-in-improving-health-and-well-being-a-scoping-review-2019.

Fancourt, D. (2017). Arts in Health. Oxford Scholarship Online. Accessed on: 2, February 2021. DOI:10.1093/oso/9780198792079.001.0001

Gendlin, E.T. (1997). Experiencing and the creation of meaning. A philosophical and psychological approach to the subjective. Northwestern University Press.

Guss-West C, Gabriele W. (2016). Attentional focus in classical ballet: a survey of professional dancers. J Dance Med Sci, 20 (1). 23-9. DOI: 10.12678/1089-313X.20.1.23

Kaufman, S. (2016). The Art of Grace: On Moving Well Through Life. Norton \& Company Ltd.

Marks, D., \& Yardley, L. (2004). Research Methods for Clinical and Health Psychology. Sage Publications.

Ryan, R. M., \& Deci, E., L. (2007). Intrinsic and extrinsic motivation in exercise and sport. In M. S. Hagger, \& N. L. D. Chatzisarantis (Eds.). Intrinsic motivation and self-determination in exercise and sport. Human Kinetics.

Seligman, M. E. P., \& Csikszentmihalyi, M. (2000). Positive psychology: An introduction. American Psychologist, 55, 5-14. https://doi.org/10.1037/0003-066X.55.1.5

Seligman, M. E. P. (2011). Flourish: A Visionary New Understanding of Happiness and Well-being. Free Press.

WHO (1948). Constitution of the World Health Organization. New York: United Nations; 1948 Accessed on: 3, January 2021 at: http://www.who.int/governance/eb/who_constitution_en.pdf 
WHO (2019). Intersectoral action: the arts, health and well-being. Accesed on: 9, February 2020 at: https://www.euro.who.int/_data/assets/pdf_file/0015/413016/Intersectoral-action-betweenthe-arts-and-health-v2.pdf?ua=1

Wulf, G. (2013). Attentional focus and motor learning: A review of 15 years. International Review of Sport and Exercise Psychology, 6, 77-104. https://doi.org/10.1080/1750984X.2012.723728

\section{About the author}

Dr. Irina Roncaglia PhD CPsychol. is a Chartered Practitioner Sport and Exercise Psychologist, HCPC registered and Associate Fellow of the British Psychological Society. She currently works for the National Autistic Society as a Clinical Lead and at the Sybil Elgar School. She is a member of the International Association Dance and Medicine (IADMS) and a member of One Dance UK. She danced professionally as a Soloist for 15 years with ENB and subsequently retrained as a Psychologist. Her research interests include Transitions, Lifespan Models, Resilience, Coping Processes \& Strategies and Performing Arts. She has completed her Doctoral research with Birkbeck University (UK) investigating the Retirement Transitions in Elite Performers.

\section{Corresponding Author's Contact Address ${ }^{[T o p]}$}

Irina Roncaglia,

24E Grosvenor Rd. W44EG,

London,

United Kingdom.

E-mail: irina@roncaglia.co.uk 